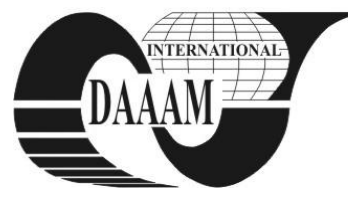

\title{
THE METHOD USED FOR BUILDING OF DRILL CUTTER FOR DEEP HOLE DRILLING
}

\author{
GORDAN, C[ornelia] E[milia]; GORDAN, I[oan] M[ircea] \& POP, P[etru] A[drian]
}

\begin{abstract}
This paper is presented a pipe workpiece with a Vee shaped at $115^{\circ}$, used in construction of drill cutters with single edge for deep hole of drilling process. The method and device realized are obtained by role pipe with a shoe support on a shaping machine-tools type SH 700.

Key words: chip, deep hole drilling, cutter, Vee roller,
\end{abstract}

\section{INTRODUCTION}

At deep hole drilling could be used and a single-edge drill. This drill is composed from head drill, shaped pipe and shank. The drill is executed by carbide inserts, the shaped pipe in Vee at $115^{\circ}$ by pipe steel and the shank by enhanced steel [Amza, 2002; Sauer, 1982]. The cool fluid and lubrication is lead inside the tool to cutting edge, and the body of drill has a cylindrical hole or oval hole and by outside of body in shaped pipe in $115^{\circ}$ Vee, once with chips exhausted (Fig.1).

The single-edge drill is used for drilling the holes between 3 - $30 \mathrm{~mm}$. The shaped pipe is obtained by pipe role Vee shaped at $115^{\circ}$ angle (Fig.2). At the series fabrication, the pipe is rolling with the shaped in Vee at $115^{0}$ on special machines. In unique fabrication of single-edge drills is very efficient the proceeding and device for cold rolling of pipe in Vee form at angle of $115^{\circ}$ on shaping machine, which was tested in toolroom shop of Machine-Tools "Infratirea" Oradea. It's started from a round stock which is rolled in successive steeps until obtaining the desired form. The reference model for the single-edge drill obtained in this company has been the Bosch drill, which had realized at equipped the transfer lines machine.

\section{THEORETICAL FUNDAMENTAL}

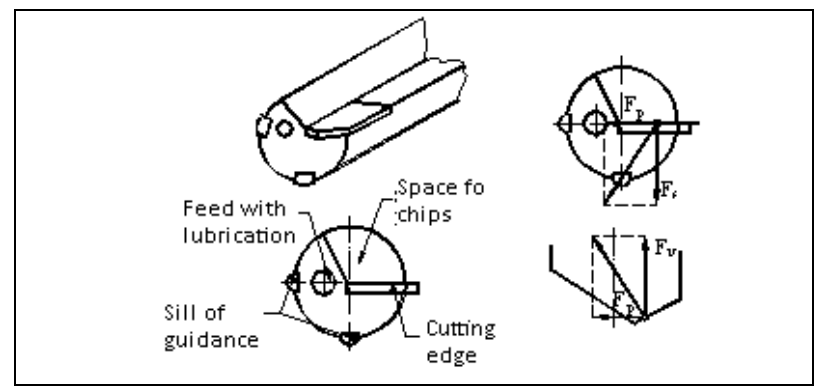

Fig. 1. Head and pipe of single-edge drill with outside exhausted of chips

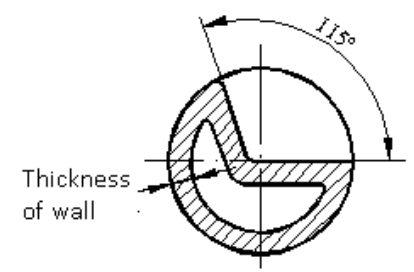

Fig. 2. The section through the shaped pipe

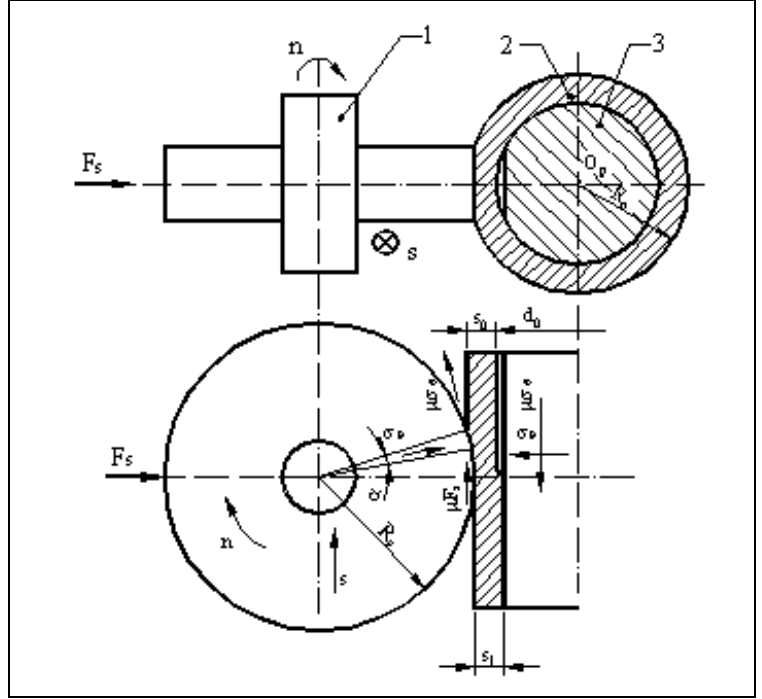

Fig. 3. The rotative table with simple differential dividing

At the base of proceeding and device is the cold rolling process of pipe by pressing on a shoe in Vee form at $115^{\circ}$.

In Fig. 3 is depicted the cold rolling-pressing process chart of pipe on shoe support. By resolved the balance equation with a formability requirement could be calculated the thin walls strain of pipes, considering that between the roller and pipe it's a linear contact pressure [Enache, 1987; Minciu, 1995]. The balance equation for the nature of axial symmetrical stress in polar coordinates is:

$$
\rho \frac{d \sigma_{\rho}}{d \rho}+\sigma_{\rho}-\sigma_{\theta}=0
$$

The formability equation is given by:

$$
\sigma_{\rho}-\sigma_{\theta}= \pm \sigma_{c}
$$

For compression is taken the sign (+), for the situation: $\sigma_{\theta}>0$, and $\sigma_{\rho}<0$. Starting from Eq. (1) and (2) and by integration resulting:

$$
\sigma_{\rho}=+\sigma_{c} \cdot \ln \rho+C
$$

Fixed the limit conditions: $\rho=R$ and $\sigma_{\rho}=0$ could be obtained the C-constant: $C=\sigma_{c} \ln R$, that is getting in Eq. (3):

$$
\sigma_{\rho}=+\sigma_{c} \cdot \ln \frac{R}{\rho}
$$

The unitary tangential stress- $\sigma_{\theta}$ is determined from Eq. (2) and changed- $\sigma_{\sigma}$ in Eq.(5): 


$$
\sigma_{\theta}=\sigma_{c}\left(1-\ln \frac{R}{\rho}\right)
$$

The maximum value of unitary radial stress- $\sigma_{\rho}$ for $\rho=\mathrm{r}$ is:

$$
\sigma_{\rho \max }=\sigma_{c} \cdot \ln \frac{R}{r}
$$

Similar, for maximum value of tangential stress is:

$$
\sigma_{\theta \max }=\sigma_{c}\left(1-\ln \frac{R}{\rho}\right)
$$

The stress of walls pipe strain is determined with relation:

$$
\sigma_{z}=\sigma_{c}\left[\ln \frac{s_{1}}{s_{0}}+\frac{\mu}{2 \operatorname{tg} \alpha / 2}\left(1-\frac{1}{2} \ln \frac{s_{0}}{s_{1}}\right)\left(1-\frac{s_{1}}{s_{0}}\right)+\operatorname{tg} \frac{\alpha}{2}\right]
$$

Where: $s_{0^{-}}$is the initial thickness of pipe; $s_{1^{-}}$is the final thickness, resulting after rolling process; $\alpha$ - is the press roll angle; $\mu$ - the friction constant roll-pipe Fixed the condition: $d \sigma_{z} / d \alpha=0$, could be determined the optimum angle- $\alpha_{o p t}$ :

$$
\operatorname{tg} \frac{\alpha_{o p t}}{2}=\sqrt{\frac{\mu}{2}\left(1-\frac{1}{2} \ln \frac{s_{0}}{s_{1}}\right)\left(1-\frac{s_{0}}{s_{1}}\right)}
$$

The press roll force- $F_{R}$ is:

$$
F_{R}=F_{d}+F_{\mu}+F_{l}
$$

Where: $F_{R}$-is the force necessary formability; $F_{\mu}$-the friction force; $F_{l}$-the elastic force. For plastic materials $F_{l}=0$. If it's taken the average pressure due to the force- $F_{R}$ :

$$
F_{R}=p_{m} \cdot s_{c}
$$

The unitary stress $\sigma_{\mathrm{F}}$ is calculated with relation:

$$
\sigma_{F}=\frac{\mu \cdot F_{R}}{s_{c}}=\frac{\mu \cdot p_{m}}{s_{c}}
$$

Where: $s_{c}$-is the horizontal projection of contact surface between roll and pipe. From relation Newman-Siebel can be determined the average pressure- $p_{m}$ :

$$
p_{m}=\sigma_{c} \frac{1}{\eta_{F}}\left(1+\frac{F}{2} \frac{l d}{s_{x}}\right)
$$

Where: $\sigma_{c}$-is ductility limit of pipe material; $\eta_{F^{-}}$efficiency of rolling. For steel-steel the friction coefficient is $\mu_{F}=0.4-0.6$.

\section{PROCEEDING AND DEVICE OF SHAPED PIPES IN VEE FORM BY ROLLING}

At "Infratirea" Oradea Co. was been realized a single-edge drill after prospects of Bosch Gmbh, by joining of drill head, shaped pipe and shank by brazed [Constantin; Cuvillier Infratirea, 2005; Bosch 2005,]. The head drill is made from cemented carbides, the shaping and drilling are machining by grinding and electrical discharge machining.

The shank is executed by classical machining process. The pipe with function of rod drill was shaped in Vee at $115^{\circ}$ by rolling-press process.
In Fig. 4 is showed the proceeding of rolling and in Fig. 5 the roll and locking device with pipe, shoe support and semicircular support. The proceeding of pipe shaping by cold rolling used a roller shaped-1 in Vee at $115^{\circ}$ is locking in device-2, which is mounted in the head of holder of shaping machine, the roller been acting by a "go-back" motion of overarm on outside face of pipe, which have a shoe support shaped in corresponding with the roll in Vee at $115^{\circ}$, getting inside of cylindrical hole, the pipe supported on semicircular slot inside of lock support on the table machining.

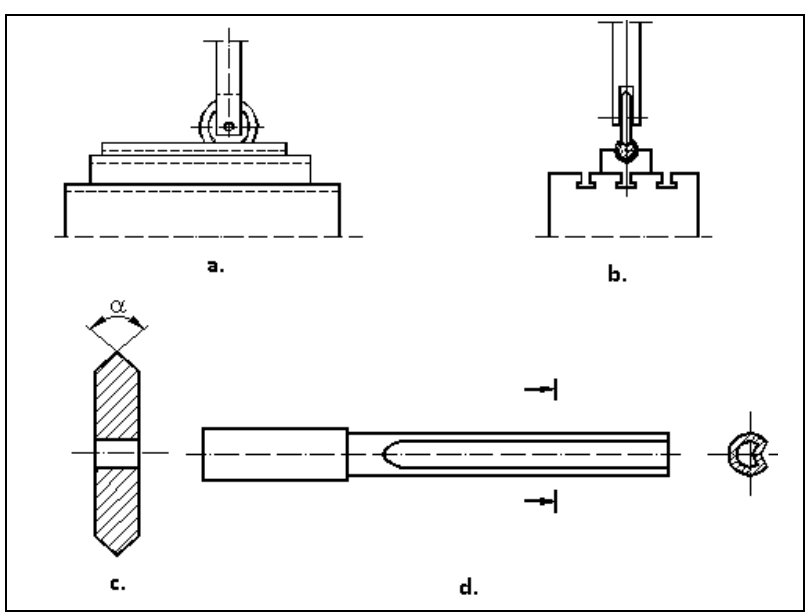

Fig. 4. Proceeding chart of shaping pipes by cold rollingpressed

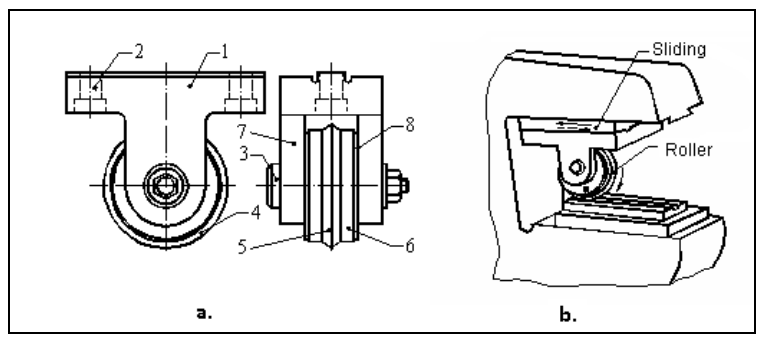

Fig. 5. The roller in Vee form at $115^{0}$ and locking support

\section{CONCLUSION}

At the end of this paper could be taken the following conclusions:

- The proceeding and device of shaping pipes in Vee at $115^{0}$ by rolling-pressed is common and easy to be done.

- The technical and quality characteristics of shaping pipe in Vee at $115^{\circ}$ by rolling-pressed on the shoe support and shaping machine are similar with the Bosch characteristics.

\section{REFERENCES}

Amza, G. et al. (2002), Treatise of material technology, Romanian Academy Ed., Bucharest

Constantin, F., The device for shaping of long pipe pieces, Patent No. 65214 Romania.

Cuvillier, G., The pipe piece and proceeding of execution, Patent No. 75232 Romania

Enache, S. et al. (1987), The technology of cutting Tools of material technology, IEEE/ASME Technical Editor, Bucharest

Minciu, C. et al. (1995), Cutting tools. Guide of design, Vol. 1, Technical Editor, Bucharest

Sauer, L. \& Ionescu, C. (1982), The deep holes drilling, Technical Editor, Bucharest

*** (2005), Technical Prospects of Bosch, Bosch Gmbh

*** (2005), Shaping machine type SH 700-A. The book of machine, "Infratirea" Oradea Co. 